\title{
A IDENTIDADE DAS PESQUISAS QUALITATIVAS: CONSTRUÇÃO DE UM QUADRO ANALÍTICO
}

\author{
ANGELA XAVIER DE BRITO \\ Centro de Pesquisas sobre os Laços Sociais - Cerlis - do Centro Nacional de Pesquisas \\ Científicas - CNRS. Université René Descartes - Paris V, França \\ debrito@ext.jussieu.fr \\ ANA CRISTINA LEONARDOS \\ Curso de Mestrado em Educação da Universidade Estácio de Sá - Unesa - \\ Rio de Janeiro. Instituto Internacional de Planejamento Educacional - IIEP - Unesco, \\ Paris, França \\ anacl@attglobal.net
}

\section{RESUMO}

O principal argumento deste artigo consiste em sugerir que seria ainda cedo para propor um novo paradigma para o campo das ciências sociais e humanas. A emergência de abordagens metodológicas qualitativas veio permitir um novo olhar sobre os fenômenos sociais, que rejeita os princípios fundamentadores da pesquisa empírico-analítica e, por conseguinte, questiona seus critérios hegemônicos de qualidade. As tentativas da última década de proclamar um novo paradigma não só denotam o embate pelo poder no meio científico mas também silenciam precocemente um debate profícuo sobre pressupostos e princípios estruturantes de um campo em plena maturação e em busca de seus próprios parâmetros de qualidade. Neste artigo, em que as experiências anglo-americana e francesa se entrelaçam, propomos um quadro/esquema de caráter essencialmente descritivo, que pretende contribuir para a melhor compreensão e análise de diversas práticas de pesquisa qualitativa. O quadro também consiste em mais uma arena de discussão sobre "qualidade" nas abordagens qualitativas de pesquisa. PESQUISAEMPIRICA-METODOLOGIA-CIÊNCIASSOCIAIS-CIENNCIASHUMANAS

Este texto surgiu do encontro das autoras por ocasião do estágio de pós-doutorado de Ana Cristina Leonardos (bolsista da Coordenação de Aperfeiçoamento do Pessoal de Nível Superior - Capes) na equipe de Recherche Associée CNRS Sociologie de l'Éducation, na qual Angela Xavier de Brito trabalhava. Especial agradecimento a Alda Judith Alves-Mazzotti (Universidade Estácio de Sá), Eric Plaisance (Université René Descartes) e Helenice Maia Gonçalves (doutoranda pela Universidade Federal do Rio de Janeiro) pela leitura crítica do texto. 


\begin{abstract}
THEIDENTITY OFQUALITATINERESEARCH:ELEMENTSFOR THECONSTRUCTIONOFA FRAMEWORK OF ANALYSIS. The main goal of this article consists in suggesting that it is still early to establish a new paradigm in the social and human sciences. The emergence of the qualitative methodological approaches has introduced a new way of viewing social phenomena, which rejects the founding principles of empirical analytical research and, subsequently, their hegemonic set of quality criteria. The attempts to proclaim a new paradigm has not only surfaced the fight for power in the scientific community but also prematurely silenced a productive debate on the inherent assumptions and principles of a field which is in a maturing process and still searching for its own set of quality parameters. In this article, where the Anglo-American and the French experience are intertwined, a conceptual framework for description and analysis is set forth with the intent of improving the understanding of different qualitative research practices. This conceptual framework also acquires the role of fostering the discussion on "quality" in the qualitative research approaches.
\end{abstract}

\title{
INTRODUÇÃO
}

Durante quase quarenta anos (1935-1970)', e apesar de dispor de um método destinado a atribuir a suas descobertas uma pretensa objetividade e universalidade, as ciências humanas e sociais ignoraram que, mais que na área das ciências ditas exatas, a pesquisa sofria por ser exercida por homens falíveis. Nem mesmo a distância assegurada por um método científico poderia controlar a influência da subjetividade própria ao ser humano, que se fazia presente durante todo o processo de pesquisa, desde a escolha dos objetos, passando pelo estabelecimento das hipóteses, seleção e recorte do campo de estudo até as análises e interpretações. Acrescentemos a isso o fato de o objeto de estudo nessa área ser o próprio comportamento humano inserido em seus contextos, em toda sua riqueza e complexidade inter e transdisciplinar.

Os vinte anos seguintes (1970-1990) assistem à recuperação progressiva da consciência da extensão da subjetividade, assim como dos vieses que ela provoca. $\bigcirc$ questionamento dos critérios objetivos e universais que fundavam essas ciências desde sua criação manifesta-se de forma diversa e em épocas diferentes em cada país, na medida em que "há uma inscrição histórica e sociocultural de todo conhecimento" (Morin, 1996, p.26). No entanto, as poucas discussões existentes sobre o assunto permanecem, com freqüência, encerradas nos limites de cada país, sem que um verdadeiro debate internacional formador de consenso se tenha podido estabelecer.

I. A data de 1935 corresponde, grosso modo, ao fim do período em que Park e Burgess ambos do Departamento de Sociologia da Escola de Chicago nos anos 20 e 30 - desenvolveram diversas pesquisas consideradas precursoras da investigação qualitativa na área de sociologia (Bulmer, 1984). 
A crise assim diagnosticada define-se, segundo alguns pesquisadores, por uma certa estagnação das descobertas de uma sociologia que, segundo seus próprios adeptos, já teria revelado tudo sobre a maneira de funcionar dos diversos setores em que ela fragmenta a sociedade para fins analíticos, sem que as conclusões fossem plenamente satisfatórias. Outros autores, como Passeron ( I99 I), atribuíam-na à ignorância de que tais ciências funcionavam segundo uma lógica própria, não popperiana. A emergência de abordagens metodológicas qualitativas vem então permitir um novo olhar sobre os fenômenos sociais, com o questionamento dos critérios de qualidade em vigor na época: a objetividade, a validade, a fidedignidade, a universalidade e a possibilidade de generalização por inferência.

Neste artigo, pretendemos mostrar que o desenvolvimento da nova lógica não ocorreu sem dificuldades, em grande parte devido à complexidade da área das ciências sociais. $\bigcirc$ material empírico sobre o qual se fundamenta o presente texto provém de uma reflexão sobre a prática de pesquisa de suas autoras e reflete suas respectivas formações acadêmicas na França e nos Estados Unidos - razão pela qual a maioria das citações serão oriundas de literatura proveniente dos dois países. Nossa análise não ignora o fato de que, em um mundo em que a comunicação se torna cada dia mais globalizada, cada comunidade científica permanece encerrada em seus próprios limites, preservando sua própria história e suas próprias referências e submetida às oscilações de suas redes de poder. Apesar de pertencerem a comunidades científicas nacionais, os autores cotejados no texto foram agrupados segundo suas afinidades de pensamento, o que os remete a uma comunidade científica mais ampla, que transcende barreiras lingüísticas, culturais e territoriais. Nossa intenção última é propor um quadro analítico essencialmente descritivo, fundado sobre a observação das diversas práticas de pesquisa, que possa levar em conta os aspectos sociais da ciência.

\section{A EVOLUÇÃO DO PROBLEMA}

A rápida disseminação das pesquisas qualitativas dentro de um campo² dominado por uma outra maneira de fazer ciência provoca um confronto entre paradigmas, em que os adeptos do paradigma empírico/positivista hegemônico afirmam que as pesquisas qualitativas realizadas sob a égide do que se convencionou chamar paradigma subjetivista/construtivista/interpretativo não passam de uma ver-

2. Quando utilizado isoladamente, o termo "campo" refere-se ao conceito introduzido por Bourdieu ( $197 \mid$ ). A expressão "campo de estudo" concerne ao domínio estudado por uma ciência. 
são mais leve e menos fidedigna da real thing da qual são feitos os bons estudos quantitativos (Eisner, Peshkin, 1990).

O exemplo da comunidade científica de sociologia na França ilustra bem esta tensão. Dominada até meados dos anos 80 pelo paradigma estrutural-funcionalista, os pesquisadores desta área negavam legitimidade às novas formas de fazer pesquisa, recusando-Ihes até mesmo o estatuto disciplinar. Além do mais, o fato de a comunidade considerar apenas as referências francesas dificultava o acesso das outras tendências a fontes qualitativas oriundas de outros países. Pesquisadores que constituíam suas comunidades de eleição em torno de correntes como o interacionismo simbólico ou a abordagem etnográfica tinham muita dificuldade em conseguir material para fundamentar seus argumentos na comunidade científica mais ampla. Foi necessário que o paradigma dominante se enfraquecesse e perdesse sua hegemonia para que as fronteiras se abrissem e a dinâmica interna dessa comunidade fosse alterada, permitindo aos grupos de eleição ultrapassar as barreiras nacionais - o que apenas se deu por volta de 1985.

Os argumentos dos adversários não deixavam insensíveis os próprios pesquisadores da linha subjetivista/construtivista/interpretativa. Tendo sido socializados dentro do mesmo paradigma positivista que criticam, para eles é muito difícil superar sua própria formação, parte do imprinting cultura/de que fala Morin (1996, p.27). Como sugerem Howe e Eisenhart (1990), teme-se que, na pressa em legitimar as práticas e os métodos adotados no "novo paradigma", os adeptos dessa linha de pesquisa não forneçam justificativas claras e adequadas para seus métodos, descobertas e interpretações. Cria-se então uma miríade de critérios de rigor e de medidas de qualidade, numa tentativa de regulamentar o campo e, assim, controlá-lo de maneira mais eficaz. A terminologia varia ao longo dos anos e segundo as correntes: "controle de qualidade" (Goetz, LeCompte, 1984); "padrões de justificação" (Howe, Eisenhart, 1990); "critérios de virtude" (Guba, 1988). O debate, no entanto, permanece o mesmo: a busca de medidas ou de critérios de rigor para a pesquisa qualitativa. De maneira geral, todos os processos de pesquisa, ainda que reivindiquem uma identidade própria, devem justificar as razões que os conduzem a adotar tais procedimentos. Se as justificativas avançadas forem convincentes e chegarem a persuadir a comunidade científica, poder-se-á, desse modo, reconhecer e legitimar uma nova linha de pesquisa. Toda tentativa que não se justifique suficientemente por alterar esta ordem será rejeitada por seus pares e condenada ao esquecimento.

O processo de legitimação do que se convencionou chamar, primeiramente, de paradigma "naturalista" (Lincoln, Guba, 1985) e, posteriormente, "construtivista" (Guba, 1990), nos Estados Unidos, ilustra bem este último ponto. Ao observar a 
tendência convergente de certas metodologias da pesquisa socioeducacional nas décadas mais recentes, esses autores sentiram a necessidade de legitimar o movimento consensual emergente e tomaram a iniciativa de definir um novo paradigma. Mas para que ele fosse reconhecido como tal foram obrigados a estabelecer critérios ontológicos, epistemológicos e metodológicos que traçavam as necessárias distinções entre o novo paradigma e aquele, até então, hegemônico. A iniciativa fez com que os adeptos das correntes metodológicas alternativas (interpretativistas, hermenêuticas, compreensivas etc.) assumissem uma identidade diante da comunidade científica mais ampla. No entanto, a reunião, sob a égide do novo paradigma, das diversas correntes e linhas de pesquisa que se desenvolveram fora do paradigma empírico/positivista, sofreu por sua precocidade, na medida em que os próprios critérios de qualidade ainda não haviam atingido o grau de amadurecimento e consenso necessários e corriam o risco de deixar-se contaminar pelos já utilizados no paradigma anteriormente dominante ${ }^{3}$. $\bigcirc$ vácuo aí deixado propicia inúmeras críticas às pesquisas pretensamente realizadas dentro do paradigma emergente (naturalista ou construtivista) e suscita um debate paralelo, visando a um novo consenso sobre os critérios de qualidade e rigor necessários para integrar o novo paradigma.

Mas como a ciência é socialmente construída, os próprios critérios de julgamento que regem tais processos foram gradualmente colocados em questão. As críticas mais difundidas censuram esses critérios pelo fato de terem sido concebidos e revistos por um pequeno grupo detentor do poder científico, visando legitimar sua própria visão do mundo. Talvez ainda mais profundas sejam aquelas que sugerem que os critérios recentemente criados sofrem a invasão insidiosa da própria visão positivista tão duramente criticada pelos adeptos do novo paradigma (Smith, Heshusius, 1986). Schwandt (1995, p. I-2) exprime claramente tal idéia quando pergunta se "o espírito subjacente às tentativas de estabelecer critérios permanentes e de atualizar um fundamento indiscutível para o conhecimento" não indicaria antes que os adeptos das abordagens qualitativas ainda não conseguiram ultrapassar o "sonho cartesiano da certeza" como única maneira de atingir "o conhecimento objetivo", pela "aplicação de critérios trans-históricos que possam nos livrar dos caprichos da perspectiva histórica". Em consonância com o pensamento de Morin ( 1990), uma parte dos pesquisadores da linha qualitativa começa a se perguntar se a busca de um "conjunto de critérios únicos" para avaliar a qualidade das pesquisas -

3. Assim, a transferibilidade, a consistência, a confirmabilidade e a credibilidade dos dados, adotados atualmente por certas linhas qualitativas, encontram uma correspondência simétrica na generalização, na validade e na fidedignidade do paradigma empírico positivista. 
ou seja, a necessidade de se apoiar em um novo paradigma - não oculta, em filigrana, o receio, ou até mesmo a recusa, da complexidade, pelo temor de não saber traduzi-la na prática. Para alcançar uma visão complexa da realidade, "é necessário compreender o modo de estruturação dos outros tipos de pensamento diferentes do nosso, e isto não só de cultura para cultura, mas também no interior de uma mesma civilização" (Morin, 1996, p.32). Fechar-se em um paradigma significa uma incapacidade de compreender e traduzir corretamente o discurso do adversário, impedindo, desta forma, o tão necessário debate de idéias e de teorias.

A tentativa de constituição de um novo paradigma - seja ele construtivista (Lincoln, Guba, 1985), subjetivista (Noiriel, 1989), ou outro qualquer - faz atualmente parte da revisão da sociologia como disciplina. Ela nos parece, entretanto, ainda prematura: no momento mesmo em que os critérios são repensados, impõe-se urgentemente uma reflexão sobre a própria necessidade de continuar a estabelecer critérios e medidas para a pesquisa qualitativa. Dada a imensa variedade de modelos de pesquisa existentes, talvez fosse mais útil e mais fecundo trabalhar no sentido de estabelecer um intenso debate que conduza a uma compreensão dos parâmetros mais amplos e mais flexíveis dentro dos quais as pesquisas na área das ciências humanas e sociais parecem se desenvolver atualmente. A definição de parâmetros que tentariam conceituar o processo de pesquisa de maneira a melhor descrevê-lo, sem prescrevê-lo, parece-nos, hoje em dia, da maior importância. Necessitamos de uma visão mais global, que possa contribuir para esclarecer as práticas já estabelecidas e comprovadas. Um quadro descritivo-analítico - no sentido da descrição densa preconizada por Geertz (1990) -, ainda que incompleto, pode, a nosso ver, ajudar a compreender a complexidade do universo da pesquisa qualitativa, do qual os pesquisadores e as relações de poder são parte integrante.

\section{A EMERGÊNCIA DA IDÉIA DO TRIÂNGULO}

Durante o colóquio Quality in human inquiry, organizado em 1995 na Universidade de Bath, várias tendências de pesquisa naquelas ciências confrontaram-se em busca de critérios de qualidade para a pesquisa qualitativa. Pudemos aí constatar que a luta pela imposição de um paradigma não ocorria apenas entre os que pertenciam a campos diferentes. Não há igualmente consenso entre os próprios adeptos do campo qualitativo, nem mesmo no seio de cada uma de suas diversas correntes. Importantes clivagens nacionais, metodológicas e éticas persistem, de tal maneira que os franceses não se reconhecem nas definições das redes anglo-saxãs, que há divergências entre os adeptos da pesquisa-ação ou da pesquisa feminista. 
Fatores como a subjetividade do pesquisador, as motivações fundamentais ao exercício da profissão, o tipo de relação estabelecida com a comunidade estudada, a primazia da produção de conhecimento, o estatuto atribuído ao senso comum, a necessidade de desconstruir as estruturas metodológicas convencionais de modo a neutralizar a ação das macroestruturas de poder, entre outros, são temas que provocam profunda discordância.

Para nós, o evento colocou em evidência a dificuldade da constituição de critérios, já que as próprias pessoas envolvidas na prática de pesquisa eram incapazes de ter clareza sobre os critérios a propor. Nesse sentido, Smith (1990), reportando-se a Kuhn, lembra que entre as condições para a mudança de paradigma estariam as mudanças nos padrões dos pressupostos subjacentes à atividade científica. Se considerarmos que critérios e pressupostos estão intimamente ligados, compreenderemos melhor as dificuldades dos participantes do colóquio. Essas considerações levaram-nos a propor um quadro analítico fundado na descrição das práticas de pesquisa que pudesse contribuir para um trabalho em direção à formação de um consenso. Tal quadro baseia-se num triângulo eqüilátero (Fig. I), em que os principais elementos constitutivos do processo de pesquisa, no nosso entendimento - o pesquisador, a literatura científica e o objeto/sujeito de pesquisa -, estão colocados em cada um dos três vértices, tendo, em princípio, o mesmo valor. As relações entre eles são expressas nas linhas de força estabelecidas ao longo das três vertentes, em que a combinação entre cada par de elementos se inscreve na relação triangular global e se beneficia de seus próprios elementos de mediação: a comunidade científica, entre o pesquisador e a literatura científica; a oposição senso comum versus senso científico, entre a literatura científica e o objeto/sujeito da pesquisa; e o filtro das metodologias de pesquisa, entre o pesquisador e o objeto/sujeito da pesquisa ${ }^{4}$. Esse triângulo eqüilátero está, por sua vez, inscrito em um círculo que representa o processo de pesquisa em seu conjunto, de cujo centro irradiam as relações de poder e um feixe de preocupações éticas que inspiram práticas ou interações. Dessa forma, o mesmo triângulo propicia inúmeras leituras, permitindo tanto a descrição da especificidade da prática de cada pesquisador e suas opções metodológicas

4. A visão de Pharo (1992) apresenta afinidades parciais com a nossa: o que ele chama de dados objetiváveis do social é para nós o objeto/sujeito da pesquisa e a figura do analista se confunde com a do pesquisador. No entanto, ele embute as metodologias de pesquisa - que, em nossa concepção, mediam a relação entre pesquisador e objeto/sujeito - no próprio pólo do pesquisador, ao incorporar ao analista suas categorias conceituais. Pensamos que o que ele chama de trabalho de interpretação dos atores aproxima-se da oposição senso comum versus senso científico, outra das vertentes do nosso triângulo. 
e éticas quanto a síntese das diversas relações de força e dos eixos de tensão presentes nos diferentes momentos da pesquisa.

A figura geométrica do triângulo - ou seja, a relação triangular - opõe-se ao fechamento binário como figura de ordenamento e simboliza, ainda, a complexidade crescente do conhecimento. Dufour (1989, p.24) vê na resistência ao ternário a fonte do "mal-estar específico de nosso século (...), dos homens e da civilização" e preconiza a necessidade de voltar a questionar a dominação exclusiva do pensamento binário na tradição das ciências humanas e sociais. Na França, vários pesquisadores trabalham para um crescente reconhecimento dos processos triangulares. Segundo Pharo, os níveis de análise que devemos tentar colocar em correlação são três: os dados objetiváveis do social, o analista com suas categorias conceituais e, entre os dois, o trabalho de interpretação dos próprios atores (Dosse, 1995, p. I 44). Caillé ( 1 989), Godbout ( 1992), baseados em Mauss, ressaltam, por sua vez, a forma triangular e o caráter indivisível do processo constitutivo da dádiva (dar/receber/ restituir) que, assim concebida, se torna "uma figura de desconstrução que barra a oposição dentro/fora, verdade/erro" (Derrida, I991, p.26).

Um tal esquema tem a ambição de facilitar a leitura e a compreensão dos processos de pesquisa qualitativa nas ciências humanas e sociais, assim como das relações estabelecidas entre seus elementos constitutivos, cujo aspecto globalizante não foi ainda bem compreendido. Cada linha de pesquisa estabelecerá um diálogo específico entre cada uma das partes e a totalidade do triângulo. Cada pesquisador irá definir-se mediante uma negociação que convenha aos recursos pessoais/materiais de que dispõe, ao seu estilo, à sua abordagem preferida, ao seu objeto de estudo, à sua inscrição numa corrente etc. Parece-nos razoável sugerir que, pelo menos no momento atual, a prática da pesquisa teria como objetivo principal e comum o estabelecimento desse diálogo, no qual o pesquisador negociará, ao mesmo tempo, consigo mesmo (com sua subjetividade), com a(s) comunidade(s) científica(s) à(s) qual(is) pertence e com o objeto/sujeito de sua pesquisa.

Desse modo, o conjunto de elementos que compõe a base das pesquisas deixa de ser prescritivo e passa a ser descritivo. No início desta década, Caillé ( 1992 , p. 3 I) já indagava "em nome de que impor aos pesquisadores uma norma ideal que não deve ser outra senão a descrição de suas práticas?" No mesmo sentido, Feyerabend ( 1979, p. I 5) opõe-se firmemente ao fechamento em torno das "prescrições epistemológicas" mais surpreendentes e propõe "a rejeição de todo princípio universal e de toda tradição rígida". Assim, o triângulo, ou quadro analítico, que propomos aqui, pode ser lido de vários ângulos, permitindo a flexibilidade necessária à análise na área das ciências humanas e sociais. 
FIGURA I

ESQUEMA DE DESCRIÇÃO DO PROCESSO DE PESQUISA

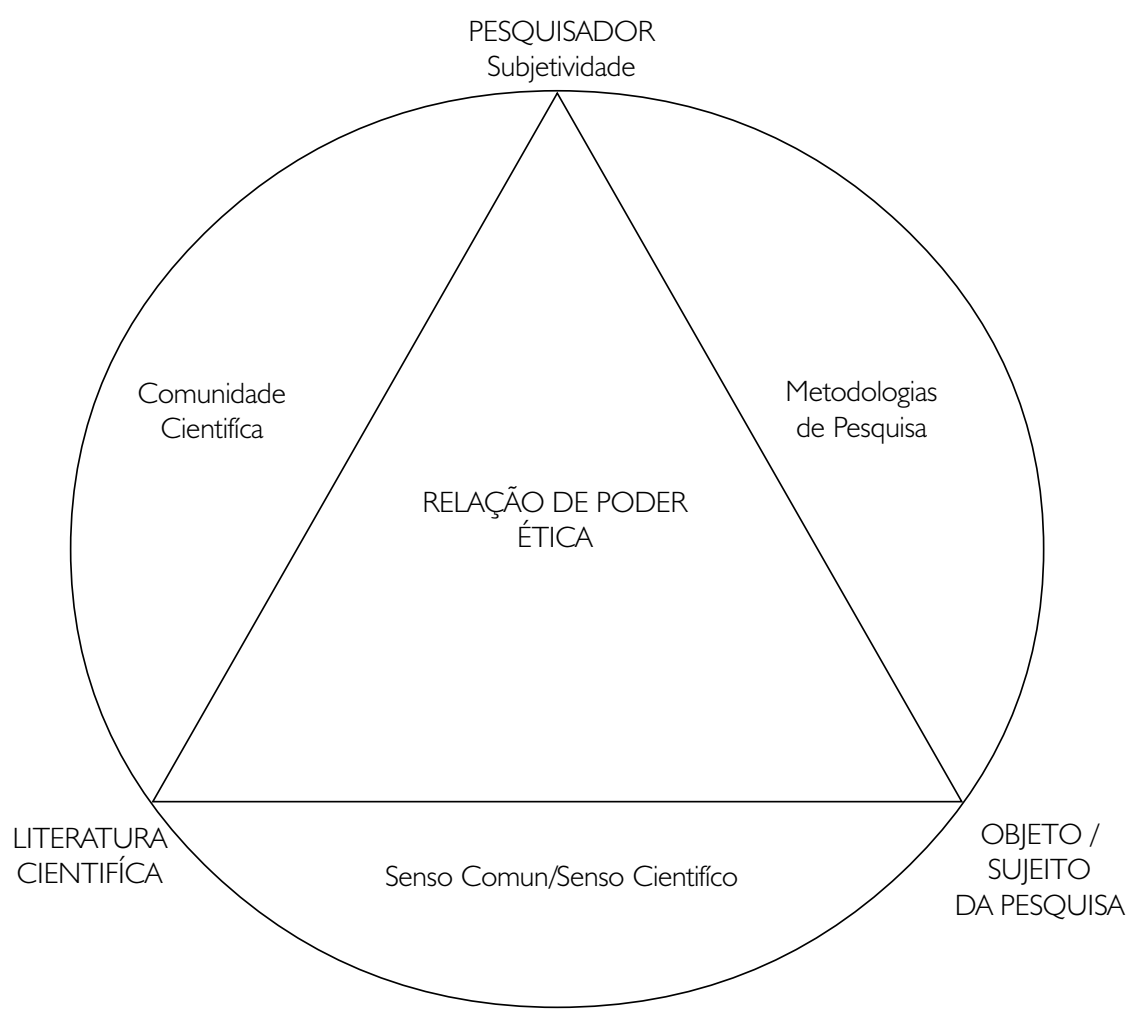




\section{O ESTATUTO DA DESCRIÇÃO EM SOCIOLOGIA}

A descrição ainda é freqüentemente considerada como uma arte menor, oposta aos imperativos da construção teórica. No entanto, vários sociólogos parecem estar de acordo com a idéia de que a descrição deveria reassumir um estatuto predominante em sociologia (Ackerman et al., 1985). Segundo Caillé (1992), a descrição é a primeira exigência do trabalho teórico em sociologia e Quéré (1992) preconiza uma postura "descritivista", em nome de uma nova epistemologia das ciências sociais.

Em nossa opinião, na atual conjuntura do desenvolvimento das ciências humanas e sociais, é mais importante compreender a forma pela qual o pesquisador se comunica com os outros participantes e estabelece a negociação no seio do processo de pesquisa do que julgar se tal negociação se realizou de maneira correta ou incorreta, a partir de critérios preestabelecidos, cuja coerência foi determinada por esta ou aquela corrente específica.

Diante de uma tal diversificação de critérios e de modalidades de excelência científica - já que todo mundo continua a reivindicar a verdade científica - seria risível pretender colocar-se na posição de julgar em nome da verdade científica. (Caillé, 1992, p.30, tradução nossa)

Ao preconizar a descrição, procuramos investir a ciência de como ela se faz, não para importar modelos pré-construídos, mas levando a sério "o que dizem os atores destas ciências e fazendo um discurso compatível com as descobertas científicas" (Dosse, 1995, p. I 5). Na medida em que "as identidades e os pertencimentos disciplinares não são evidentes e não gozam de nenhuma forma de naturalidade" (Caillé, 1992, p. 12), a etapa da descrição parece-nos imprescindível. Talvez a maior aceitação da complexidade do processo de pesquisa nas ciências humanas e sociais nos faça chegar a maior abertura e tolerância com relação a nossos pares e, conseqüentemente, a maior heterodoxia - importantes passos na direção de um consenso.

Procuramos assim, ao propor o triângulo como forma de ordenamento da descrição na área das ciências sociais, insistir na idéia de que toda pesquisa é uma forma de relação social, que ganha força ao ser analisada dentro do espírito da teoria da dádiva, como já o fizeram Brito (1994) e Brito e Vasquez (1999). Afinal, a relação triangular representa "a essência do laço social, porque sem ela não haveria relação de interlocução, não existiria cultura humana" (Dufour, 1989, p. I I I). O triângulo seria uma forma de organizar o campo, em primeiro lugar, porque se 
origina na prática real de pesquisa das diferentes correntes - e não de uma prática idealizada. Nesse sentido, ele tende a explicar o funcionamento do processo de pesquisa na área das ciências humanas e sociais a partir desse ponto de interseção: a própria prática do pesquisador, assim como sua capacidade de descrever perspectivas, posturas ideológicas, relações, conflitos e procedimentos adotados em seu trabalho. Em segundo lugar, ao partir do que já existe, ele não exclui, como fazem as listas de critérios de rigor; ao contrário, destina-se a incluir, mediante o debate. Ao permitir a descrição, ele facilita ao mesmo tempo a explicação mais ampla das dinâmicas possíveis de pesquisa.

À objeção de Caillé (1992, p.20), de que "hoje em dia se torna cada vez mais difícil proceder a uma descrição ordenada da produção em ciências sociais, tão grande se tornou a diversidade, de tal forma que as entradas da grade descritiva deveriam ser inúmeras", respondemos que nossa intenção, ao propor os elementos do triângulo, é analisar sobretudo as relações humanas inerentes ao processo de pesquisa. Por essa razão, privilegiamos, entre os muitos indicadores possíveis, as multifacetadas relações entre o pesquisador, os sujeitos da pesquisa e a(s) comunidade(s) científica(s) de eleição reificada(s) em sua produção.

\section{OS TRÊS VÉRTICES DO TRIÂNGULO $\mathrm{O}$ pesquisador}

Dois pontos-chave devem ser observados com relação à figura do pesquisador. $\bigcirc$ primeiro é sua posição de poder; o segundo, a influência de sua subjetividade.

No que se refere à posição de poder, existe um consenso implícito entre autores das ciências sociais de que, independentemente da corrente metodológica adotada, o pesquisador detém uma posição de poder no processo de investigação. Por essa razão - e ainda que nosso esquema se baseie em um triângulo eqüilátero, que visa ao equilíbrio entre seus componentes - a figura do pesquisador foi colocada em seu ápice. Como dissemos acima, o triângulo busca descrever o que se passa efetivamente no processo de pesquisa. Neste sentido, não se pode fugir à evidência de que "o papel do pesquisador é diferente do ator social e geralmente estimado como mais importante” (Schön, 1996, p.203). Além disso, existe uma hierarquia estatutária na representação que os próprios objetos/sujeitos de pesquisa têm do pesquisador. Diante deste último, os participantes da pesquisa agem como se ele fosse o sujeito de suposto saber - na medida em que é ele quem detém o poder de atribuir sentido às informações coletadas no campo. 
Não basta ter a intenção de alterar essa realidade para que as mudanças sejam realizadas. Mas uma outra constatação impõe-se aqui: a de que as diversas correntes de pesquisa tratam o problema com base em pressupostos diferentes, ou mesmo divergentes. Embora algumas correntes - entre as quais nos incluímos - estimem que seus compromissos éticos impeçam seus participantes de fazer uso explícito do poder atribuído ao pesquisador e considerem que seus respectivos estatutos devam ser negociados durante o processo de pesquisa, de forma a estabelecer uma relação de eqüidade que respeite as especificidades de seus papéis, as dificuldades para relativizar a posição de poder do pesquisador são inúmeras - entre as quais a própria representação que os sujeitos da pesquisa têm sobre esse poder.

O paradigma positivista coloca claramente o princípio da legitimidade do estatuto superior do pesquisador, na medida em que é ele quem "toma todas as decisões sobre as condições na qual se realiza a pesquisa e sobre a natureza das intervenções realizadas sobre seus objetos" (Dobbert, 1990, p.287). Essa corrente vê o pesquisador como o único responsável pela atribuição de sentido, inspirandose na ruptura epistemológica preconizada por Bachelard. House ( 1990 ) sugere ainda que o poder do pesquisador advém, entre outras coisas, do tratamento e do uso que este fará da informação obtida. Os esforços da chamada linha neopositivista não questionaram tal supremacia.

As correntes qualitativas consideram que assumir e defender essa posição é uma atitude bastante arrogante. Mas, apesar dos esforços no sentido contrário, a arrogância não é apanágio dos pesquisadores inscritos no paradigma positivista: Dobbert identifica, dentro da pesquisa qualitativa, posições que, sob a máscara do igualitarismo, contêm posturas que conferem implicitamente ao pesquisador uma posição de força. Segundo a autora,

...somos arrogantes quando recusamos discutir sobre nossos procedimentos de pesquisa e nossos paradigmas, adotando uma atitude de auto-satisfação que nos faça apenas querer "ir em frente"; quando não solicitamos perspectivas críticas que contribuam para liberar nosso próprio pensamento, ou não pedimos àqueles que estudamos que nos ajudem a liberar-nos; ou ainda, quando decidimos que os pesquisadores podem conferir poder ${ }^{5}$ aos demais participantes de uma pesquisa. (1990, p.287, tradução nossa)

Na verdade, as pesquisas que promovem o empowermentreconhecem implicitamente que as interações pesquisador-sujeito são permeadas pelas relações de

5. No original, a palavra empregada é empowerment, que não tem tradução em português. 
poder: nesse contexto, o pesquisador que pretende conferir poder aos demais participantes da pesquisa se auto-representa como uma figura todo-poderosa, na medida em que só se pode conferir ao outro o que se detém. Mas os adeptos dessa corrente ignoram, com freqüência, que, mesmo nas abordagens metodológicas que não prevêem a "entrega" do poder aos sujeitos, estes sabem tirar partido para proveito próprio do poder efetivo ou atribuído aos pesquisadores (Brito, 1994; Leonardos, 1990)6.

Outro ponto fundamental a ser discutido refere-se à questão da objetividade/subjetividade do pesquisador diante do processo de investigação. Tradicionalmente, o papel do pesquisador definia-se por uma crença em sua capacidade de investigação isenta e distanciada. Hoje em dia, até mesmo os pesquisadores na área das ciências exatas reconhecem que a objetividade absoluta e uma ciência livre de valores são ideais impossíveis de serem atingidos na prática (Lévy-Leblond, Jaubert, 1975; Elias, 1983; Habermas, 1973). Na área das ciências sociais, a influência da subjetividade pode ser detectada até mesmo na formulação ou na seleção das questões de um survey - instrumento clássico que remete ao não-envolvimento e à imparcialidade do pesquisador que o planeja - na medida em que as opções ideológicas ou filosóficas estão subjacentes à aparente objetividade de um questionário. Segundo Patton (1990, p.55), os termos objetividade e subjetividade "tornaram-se munição ideológica para o debate entre os paradigmas": a palavra subjetividadeteria adquirido uma conotação tão negativa que o pesquisador que defende abertamente o valor da percepção subjetiva na pesquisa corre o risco de prejudicar a credibilidade do seu próprio trabalho.

No entanto, o reconhecimento da subjetividade do pesquisador como pessoa humana historicamente situada, dotada de atributos e interesses provenientes de sua posição de classe, etnia, gênero, idade e orientação sexual foi, na verdade, uma preciosa contribuição no sentido de maior objetividade do processo de pesquisa. Bourdieu e Passeron ( 1970) dizem que a ocultação de um fenômeno contribui para redobrar sua força de ação. Pensamos que, ao invés de negar sua subjetividade, o pesquisador deve procurar ter consciência dela durante todo o processo de pesquisa, analisando-a como mais um dado desse processo. Na medida em que a análise da subjetividade não é evidente, vários autores preocuparam-se em sugerir maneiras de realizá-la. Por exemplo, LeCompte ( 1987 ) sugere que os pesquisa-

6. Estes trabalhos apresentam evidências de como os indivíduos no campo de pesquisa sabem fazer uso da presença do pesquisador para conseguir contatos, obter informações necessárias, realizar seus próprios objetivos de poder etc. 
dores se submetam ao que ela chama de uma "psicanálise intelectual" que Ihes permitiria estar conscientes das influências de sua formação e de seus interesses antes mesmo de começar a pesquisa. Já Peshkin (1982; 1991) adota uma atitude cumulativa, que consiste em analisar detalhadamente como sua subjetividade incidiu em suas pesquisas passadas, para evitar as mesmas armadilhas nas futuras. Brito ( 1994) sugere, por sua vez, que essa análise auto-reflexiva da subjetividade seja constante e integrada no próprio desenho da pesquisa. Uma outra forma de evitar a influência da subjetividade é a que utiliza a corrente da intervenção sociológica (Dubet, 1999), preconizando um trabalho conjunto de equipes que estudam o mesmo objeto e comparam mutuamente os resultados.

Assim, para nós, descrever o vértice do triângulo que cabe ao pesquisador implicaria, antes de mais nada, descrever como ele lida com a tensão imanente contida nas relações intrínsecas e complexas de poder que permeiam o ato de investigação e que estatuto ele se atribui nesse jogo de poder. Implica igualmente ver como ele se situa no contexto da tensão necessária entre objetividade e subjetividade. Nesta parte, caberia, ainda, verificar que meios, estratégias, métodos e procedimentos ele adota para analisar sua subjetividade, de tal forma que tais recursos possam ser partilhados por outros pesquisadores.

\section{A LITERATURA CIENTÍFICA}

Publicar, contribuir para a elaboração e a difusão do conhecimento, é tarefa essencial de todo pesquisador - a tal ponto que um conhecido artigo americano coloca a opção de "publicar ou morrer" academicamente (Caplow, McGeer, 1968). A formação da identidade de um profissional da área das ciências sociais está em estreita relação com sua produção científica. Não é por acaso que instituições universitárias e organismos de fomento à pesquisa de vários países, inclusive a Coordenação de Aperfeiçoamento do Pessoal de Nível Superior - Capes - e o Conselho Nacional de Pesquisa - CNPq - no Brasil, tomam como indicador básico de eficiência de um cientista o número de livros e artigos já publicados. Nos Estados Unidos, o Citation index tornou-se referência quase obrigatória na avaliação da produção de um pesquisador. A freqüência e o contexto (de crítica ou de apoio) em que um autor é citado revelam o grau de penetração de sua obra, pela criação ou pelo embasamento prestado a idéias e conceitos.

Foi por essa razão que a incluímos em um dos vértices do triângulo, a literatura científica produzida e consultada por um pesquisador. Como indicador relevante de sua área de atuação no seio da comunidade científica disciplinar a que 
pertence, ela pode revelar, ao mesmo tempo, seu grau de poder acadêmico, o reconhecimento de que é alvo, as comunidades às quais se filia. A literatura científica se constrói tanto a partir de um desejo de contribuir para a construção do conhecimento pela difusão de suas idéias quanto a partir de lutas de poder travadas por pesquisadores em busca de reconhecimento e notoriedade. Os trabalhos de um autor refletem sua adesão/exclusão a grupos específicos, chegando a ultrapassar as barreiras disciplinares - como sugere a noção de "comunidade persuasiva" introduzida por Allen, Qin, Lancaster (1994).

Pensamos que a análise da literatura científica revela, ainda, sobre um pesquisador :

a. vitalidade de seu pensamento: trata-se de verificar não apenas como ele lida com os métodos tradicionalmente constituídos, mas também o grau de inovação teórico-metodológica de sua obra; de que maneira se faz sua inscrição em uma corrente de pensamento, se apenas como mais um adepto ou como uma pessoa que trabalha para a ampliação e o questionamento dos insumos que recebeu em sua formação e prática de pesquisa. Ou seja, parodiando Sartre ( 195 I), seus textos mostram o que ele faz do que os outros fizeram dele. Esse ponto pode ainda ilustrar sua contribuição efetiva para a construção de sua disciplina, assim como sua reputação nacional ou internacional.

b. visão epistemológica: a organização dos textos de um pesquisador mostra qual é sua relação com o conhecimento e sua concepção do processo de pesquisa. Com efeito, se alguns pesquisadores se limitam a apresentar uma problemática, as escolhas conceituais para compreendê-la e os resultados obtidos, outros vão bem mais longe na explicitação de sua posição teórico-metodológica: buscam expor como emergiu a questão que deu origem à pesquisa, ou seja, a gênese da problemática; quais as negociações necessárias para coletar o material de análise; qual sua relação com problemas tão fundamentais quanto a descrição ou a explicação.

c. grau de abertura e diálogo a que ele se propõe: este ponto pretende analisar se o pesquisador se fecha em sua comunidade de origem ou se está aberto ao diálogo com outros pesquisadores e outras comunidades, seus projetos e ambições em direção à interdisciplinaridade. Como toda a pesquisa em ciências sociais, este ponto é fortemente condicionado pela inscrição histórico-geográfica de seu trabalho. Com efeito, as comunidades 
científicas dos diferentes países apresentam diferenças quanto à sua forma de incitar ao diálogo. Se a comunidade intelectual anglo-saxônia estimula a circulação de textos intermediários expressamente destinados ao debate e tem o hábito de incluir artigos de crítica e resposta nos suportes de publicação, a tradição é ainda bastante rara na França. Por exemplo, os organizadores da mais recente conferência de etnografia de educação da Universidade de Oxford (setembro de 1999) chegaram a sugerir que os autores apresentassem textos não completamente trabalhados, with a few ragged ends ${ }^{7}$, no sentido de facilitar ainda mais aos colegas a crítica de seus trabalhos. A análise da bibliografia (ou da ausência de bibliografia) proposta por um pesquisador em seus livros e artigos pode também oferecer pistas para a compreensão de sua posição. A seleção dos nomes aí mencionados aponta para sua comunidade de eleição ou de persuasão. Também o cuidado com que referencia suas fontes indica o grau de respeito para com seus interlocutores e sua disponibilidade para que seus pares possam verificar a exatidão com que as cita.

d. indicações sobre sua postura ética: se a linguagem utilizada por um pesquisador em sua produção revela, por um lado, sua inscrição em uma corrente de pensamento, a homogeneidade de seu referencial teórico, a adequação entre idéias e conceitos, por outro lado, ela pode dar preciosas pistas quanto à sua relação com os objetos/sujeitos da pesquisa ou quanto à dimensão ética do seu pensamento, como veremos abaixo.

A leitura cuidadosa da obra de um pesquisador fornece indícios importantes sobre a relação que ele mantém com os demais participantes do processo de pesquisa, em vários níveis. No entanto, não basta apenas ver o que o pesquisador diz em seus textos. É igualmente necessário verificar o que ele não diz: o que omite em seus textos, ou seja, o que ele rejeita para a "casa vazia" (Deleuze, 1973), é tão significativo quanto o que explicita.

\section{O OBJETO/SUJEITO DA PESQUISA}

Partindo do pressuposto do papel expressivo da linguagem na revelação do posicionamento teórico-metodológico e ético do pesquisador, fizemos questão de

7. Esta frase - que significa literalmente "com algumas pontas soltas" - implica que os textos apresentados não devem ser muito elaborados nem conter um raciocínio fechado. 
deixar essa ambigüidade clara na própria forma de intitular este vértice do triângulo. Na verdade, a maneira de intitular os participantes da pesquisa - objeto ou sujeito é um indicador poderoso do estatuto que lhes é atribuído pelo pesquisador: de um lado, os que se limitam a estudá-los, objetivando-os para que correspondam ao arcabouço teórico que os despoja de sua humanidade; de outro, os que aceitam sua participação no processo de pesquisa em diversos graus. Uma visão apressada da questão pode reduzir a tensão entre pesquisador e participantes da pesquisa a duas oposições nocionais - objeto/sujeito, de um lado; e do outro, agente/ator como se essas noções se seguissem de maneira paralela e teleológica.

Mas não somente o objeto não se confunde necessariamente com o agente, como não há uma identificação imediata entre atore sujeito. Na verdade, o processo de construção das ciências sociais é muito mais complexo. Se o ser humano é, desde o início, considerado como um "objeto" em sociologia, é, em parte, em razão do contexto no qual se desenvolveram as idéias dos principais fundadores dessa disciplina - Comte, Durkheim -, inseridos na corrente positivista da ciência que dominava sua época. Durkheim, particularmente, preocupou-se em determinar as fronteiras da disciplina no fim do século $X I X$ e início do século $X X$, em oposição à filosofia, à psicologia mas também às correntes evolucionistas preponderantes à época, na etnologia (Kauffman, 1999). O que estava em jogo era, de um lado, a denominação de sujeito própria à filosofia e, de outro, o esclarecimento de como se dava a relação entre o indivíduo, a cultura e o fato social.

Ainda aqui sente-se a influência da história da disciplina em cada país: nos Estados Unidos, a Escola de Chicago começa a utilizar a denominação atornos anos 20/30, enquanto a Europa deve a Max Weber (1956) e à sua sociologia compreensiva a utilização do termo. Ainda assim, no contexto francês, dominado pelo paradigma positivista durante muitos anos, o ator - aquele que age de moto-próprio - cede o lugar ao agente - aquele que é determinado pelas estruturas sociais. A preponderância do paradigma estrutural-funcionalista manteve, por muito tempo, "a ilusão de um abismo estático e incomunicável entre duas entidades diferentes, o 'sujeito' e o 'objeto'" (Elias, 1983, p.63) e fez com que certos autores considerados entre "os pais fundadores da sociologia" (como Weber, Simmel, Mauss) fossem durante longo tempo relegados ao esquecimento ou apenas utilizados fora do contexto global de sua obra. A França teve que esperar pelo lançamento do livro de Alain Touraine, Le Retour à l'acteur, em 1984, para que essa forma de designação fosse difundida. A tensão entre essas duas formas remete assim à questão fundamental da liberdade relativa do ser humano. No entanto, intitular o ser humano de ator pode ocultar outros desígnios. $\bigcirc$ individualismo metodológico sempre considerou o indivíduo 
em sua posição de ator, recusando o termo agente. No entanto, a liberdade atribuída ao indivíduo no contexto da corrente é apenas teórica, e a figura do ator não é mais do que uma abstração, na medida mesmo em que se ignora os condicionantes que limitam essa liberdade.

Por sua vez, a denominação objeto remete à capacidade de distanciamento entre o pesquisador e o que ele estuda. A visão de que o "objeto" da sociologia é o homem inserido em seus contextos é relativamente recente. Em seus primórdios, o objeto desta disciplina era o fato social, o que tornava necessária a objetivação do ser humano para aceder ao conhecimento, não do indivíduo - abordagem própria à psicologia - mas das leis sociais que o regiam. Bourdieu, Passeron e Chamboredon ( 1973) chegam a dizer, em seu livro Le Métier de sociologue, que "a maldição da sociologia é ter que lidar com objetos dotados de palavra" - e que, em conseqüência, resistem mais ao necessário processo de objetivação. $\bigcirc$ termo sujeito é introduzido bem mais tarde, sob a influência da filosofia humanista - Emmanuel Mounier, sobretudo Paul Ricœur -, e remete à capacidade reflexiva do ator sobre sua própria prática.

No que se refere mais precisamente à relação entre os participantes do processo de pesquisa, a utilização dos termos objeto ou sujeito remete ao estatuto conferido pelo pesquisador aos homens cuja prática deseja compreender. Como objetos de uma pesquisa, os seres humanos investigados estão submetidos à forma de interpretação do pesquisador, sem que tenham voz ativa nesse processo. Essa forma de interpretação, que separa radicalmente a vivência do conceito, encontra oposição nas correntes qualitativas, na medida em que não só percebem e respeitam o indivíduo como responsável por suas ações e opiniões, mas consideram-no capaz de elaborar uma forma de conhecimento sobre a realidade que o circunda. Mais recentemente, essas correntes passam a aceitar a contribuição dos homens que estudam na compreensão dos processos analisados e tornam-se capazes de empreender um processo de co-construção do conhecimento buscado.

Se insistimos em inscrever em um dos vértices do triângulo a dualidade explícita entre objeto e sujeito da pesquisa, é que a escolha do termo de referência para qualificar quem se estuda indica já uma diferença entre as correntes quanto à posição de poder reivindicada pelo pesquisador, assim como uma postura ética e/ ou ideológica. A linguagem adotada pode ser suficientemente polissêmica para esconder sentidos diversos. Assim, por exemplo, a denominação de objeto atribuída aos atores da pesquisa, mesmo em um quadro qualitativo, remete a resquícios de uma outra epistemologia, em que o fato social era analisado como uma coisa, na qual "a disjunção entre sujeito (ego cogitans) e objeto (res extensa)" mutila a ativida- 
de científica (Morin, 1996, p.31). Da mesma forma, a denominação ator não é necessariamente sinônimo de sujeito - como no quadro do individualismo metodológico. As linhas de pesquisa que continuam a considerar como objetos os alvos de seus estudos situam-se, evidentemente, mais perto dos cânones de uma sociologia tradicional: ainda não fizeram uma reflexão sobre os processos de objetivação como garantia da distância entre pesquisador e pesquisados, como quanto à propriedade do pesquisador ser o único veículo de atribuição de sentido. É nessa direção que Luc Boltansky (apud Dosse, 1995) questiona a teoria da reprodução, que apresenta "um mundo totalmente objetivado, sem sujeito" apesar de pretender "levar em conta a experiência dos atores sociais".

É, assim, extremamente importante "revisitar os recortes clássicos entre objeto e sujeito" (Dupuy, 1982, p.274). Por isso, o ponto central a descrever aqui é a maneira pela qual o pesquisador se refere, em sua produção científica, às pessoas ou às comunidades que estuda - tradução do respeito que lhes manifesta e do estatuto que atribui ao seu papel na compreensão de suas práticas.

\section{OS TRÊS LADOS DO TRIÂNGULO}

Até o momento, discutimos separadamente, para fins analíticos, cada um dos elementos do processo de pesquisa. No entanto, temos ampla consciência das limitações desse procedimento. Pensamos, como Elias ( 1 983), que um tal procedimento analítico - que visa conhecer o todo pela decomposição de suas partes - é inadequado quando temos a ambição de reconstituir configurações complexas. A simples justaposição dos elementos do triângulo é insuficiente; são os sistemas de relações entre esses elementos - os quais passamos a analisar agora - que poderão contribuir de forma mais acurada ao conhecimento do processo de pesquisa.

\section{A RELAÇÃO PESQUISADOR/LITERATURA CIENTÍFICA}

Esta seção visa esclarecer a mediação exercida pela comunidade científica na legitimidade e na difusão do conhecimento.

Como já foi dito na seção dedicada à literatura científica, na descrição do trabalho de um pesquisador, um dos indicadores obrigatórios é o tipo de literatura científica por ele consultada, utilizada ou citada em seus trabalhos, as fontes que informam sua prática científica. A relação estabelecida entre os pesquisadores e a literatura passa necessariamente pela mediação da comunidade científica, enquanto esta se define pela própria relação autor/leitor, na qual pessoas lêem os trabalhos 
uns dos outros ou estabelecem comunicações informais (Allen, Qin, Lancaster, 1994). A literatura selecionada pelo pesquisador está em estreita relação com o tipo de relações acadêmicas que estabelece, com os círculos por ele freqüentados, com a linha de pesquisa à qual ele se filia, com as redes de pesquisa às quais pertence etc. Na verdade, a literatura nada mais é do que uma reificação do conhecimento científico produzido por esse grupo de referência. Assim, a mediação principal entre o pesquisador e o conjunto de referências bibliográficas que ele utiliza passa necessariamente pelas relações sociais que ele seleciona dentro da comunidade científica à qual pertence, por estar inscrito dentro de uma área disciplinar.

Parece-nos evidente que todo pesquisador está, em princípio, inserido nos marcos de uma comunidade cientíica mais ampla, que se inscreve em uma disciplina determinada, que define os limites de sua maneira de fazer ciência. Nesse sentido, uma das definições de paradigma fornecidas por Kuhn (1990, p.393) está em ligação estreita com o conceito de comunidade científica: "Um paradigma é o que compartilham membros de uma comunidade científica e somente eles". Contudo, há nessa concepção um risco iminente, na medida em que as regras do campo podem impedir a emergência de grupos inovadores, sempre que o paradigma globalmente adotado manifesta suficiente coesão. Torna-se assim difícil a formação desses pequenos grupos de eleição que se constituem, em princípio, pela partilha de referências e de critérios comuns e pelo exercício de uma prática similar de pesquisa - uma das maneiras de assegurar a cumulatividade necessária a todo saber científico - sobretudo quando eles reivindicam referências que colocam em questão o paradigma global. Com referência a essa comunidade, Popper, segundo Morin, insiste em dois aspectos muito importantes.

O primeiro, é que haja um consenso não apenas sobre as regras do jogo, mas também sobre as aspirações profundas ao saber, à verdade, e até sobre um certo número de valores e crenças quanto à missão da ciência. O segundo, é que não basta que haja o consenso da comunidade - comunidade que é gemeinschaft -, é necessário que haja também aspectos de sociedade - gesel/schaft-, aspectos de rivalidade e de conflito. É necessário que haja oposições entre as teorias e, por trás das oposições entre as teorias, a oposição das idéias metafísicas não ditas. É necessário também, mesmo que isso seja penoso, que haja oposições e conflitos pessoais, que podem resultar dos humores, das antipatias, das ambições e das frustrações. (1996, p. 16)

As relações de poder também estão presentes dentro dessa comunidade científica de eleição, como estão presentes na comunidade científica mais ampla, em que cada disciplina científica busca assumir uma posição hegemônica, chegando 
a reduzir ao silêncio as disciplinas minoritárias, como denunciaram Stenghers e Bensaude-Vincent ( 1993). O fato de essa comunidade ser escolhida livremente pelo pesquisador não o deixa imune à influência das regras que, segundo Bourdieu ( 197|), definem o funcionamento de todo campo: regras impostas aos recém-chegados, regras de aceitação, legitimidade e reconhecimento pelos pares, regras éticas e deontológicas, hierarquias diversas e também, como assinala Caillé (1986), as resistências da comunidade para reconhecer e legitimar abordagens inovadoras.

\section{RELAÇÃO PESQUISADOR-OBJETO/SUJEITO DA PESQUISA}

Visamos, aqui, mostrar o papel de mediação exercido pelas opções metodológicas do pesquisador. Com efeito, o elo que une o pesquisador e seu campo de pesquisa é a metodologia, entendida neste caso como

.... que se refere às relações das várias partes do estudo com a produção de dados/ informações (...), que se preocupa com a ordem moral (regras, valores, prioridades, dadas às condições sociais e à ação individual) pressuposta na prática das ciências. É o estudo do que é definido como conhecimento legítimo e de como este conhecimento é obtido e organizado. (Popkewitz, 1990, p.5I-2, tradução nossa)

Na metodologia, o pesquisador "evidencia as opções que fez e de que modo essas escolhas são adequadas ao problema de pesquisa” (Dobbert, 1990, p.289). Partimos assim da premissa de que toda escolha do equipamento conceitual e operacional a ser adotado em um estudo ocorre em razão de uma interação entre o objeto a conhecer e a personalidade do pesquisador e, por isso, mais do que fornecer informações, denota "maneiras de se expressar relações no mundo que nos permitem entender algumas das questões fundamentais subjacentes à 'modernidade' do mundo em que vivemos" (Popkewitz, 1990, p. 65). Daí a importância de explicitar-se e justificar as opções metodológicas contextualmente, mediante descrição dos procedimentos priorizados e das formas pelas quais as informações foram obtidas e sistematizadas, na medida em que só assim estaríamos praticando ciência com um "forte senso de epistemologia social, isto é, da inter-relação da ciência com as condições históricas dentro das quais ela funciona" (Popkewitz, 1990, p.65). O autor rejeita o registro e a análise de eventos e fatos de maneira isolada das ocorrências históricas, por meio de técnicas qualitativas ou quantitativas, defendendo a inclusão da história como parte lógica da organização interna de uma determinada ciência.

Ao mesmo tempo, é mediante suas escolhas metodológicas que um pesquisador delimita formas de construção do conhecimento e possibilidades de interação 
com o objeto/sujeito. $\bigcirc$ tipo de relação de poder, a hierarquia estabelecida entre o pesquisador e o objeto/sujeito de pesquisa também decorrem do método adotado e vão influir diretamente na forma de produção do conhecimento, como já comentamos amplamente. Na França, por exemplo, alguns grupos de pesquisadores inclinam-se cada vez mais em direção a uma orientação metodológica que considera o processo de atribuição de sentidos como uma relação a ser construída entre o pesquisador e aqueles a quem estuda, na qual o sujeito da pesquisa e o pesquisador fazem ambos parte de uma relação de interpretação que implica a intersubjetividade e não mais como algo outorgado a partir do exterior, dentro da perspectiva metodológica inspirada em Durkheim, que concebia o fato social como uma coisa.

Mas essa relação que leva à co-construção do conhecimento não é simples de ser obtida. Como vimos acima, as correntes de pesquisa que radicalizam ao máximo tal posição, chegando a delegar ao objeto/sujeito o poder de escolha do problema a ser estudado, não conseguem inverter completamente a ordem hierárquica, na medida em que ainda é o pesquisador quem define, quase sempre de cima para baixo, as necessidades de teoria que têm os atores sociais. A questão é uma das mais difíceis de resolver para o pesquisador, na medida em que a postura de reconhecimento de um estatuto não idêntico, mas justo, ao senso comum, pode dar-lhe a impressão de que está perdendo o controle sobre o processo de pesquisa. Alguns pesquisadores já comentaram, em círculos de estudo, como é difícil constituir uma verdadeira relação de colaboração entre pesquisadores e sujeitos da pesquisa, em que os dois atores possam considerar que ocupam posições diferentes, mas equivalentes, pois a contribuição do senso comum é ou desvalorizada, ou superestimada.

Há assim necessidade de se repensarem e de se reconstruírem os papéis do pesquisador e do ator social dentro da prática de pesquisa. De todas as maneiras, não pretendemos resolver a questão neste artigo; tratamos apenas de indicar que o lugar atribuído ao senso comum no sistema de pesquisa é um importante indicador dessa complexa relação entre o pesquisador e o objeto/sujeito da pesquisa. Analisar a forma pela qual ele é aceito e compreendido pelas diversas correntes torna-se assim indispensável ao processo de produção do conhecimento.

\section{A RELAÇÃO ENTRE LITERATURA E OS OBJETOS/SUJEITOS DA PESQUISA}

Nosso objetivo, nesta parte do trabalho, é mostrar como se estabelece a relação entre ciência (ou senso crítico) e senso comum. A pesquisa qualitativa em ciências humanas e sociais "exige um acesso particularmente direto ao pensamento 
e à ação dos atores sociais" (Schön, 1996, p.222). É por sua produção científica que melhor se pode avaliar a posição que um pesquisador estabelece com os objetos/ sujeitos de pesquisa no que se refere à produção do conhecimento. Podem-se colocar várias questões a este respeito: que estatuto atribui o pesquisador às elaborações que os atores sociais fazem das experiências por eles vivenciadas? Limita-se a coletá-las como dados "neutros", cuja análise poderá ser apenas feita por ele mesmo, como pesquisador, na medida em que se concebe como o único detentor do saber científico? Considera os demais participantes da pesquisa como também exercendo o papel de pesquisadores em um contexto prático, na medida em que sua reflexão apresenta semelhanças com o funcionamento do que se convencionou chamar "método científico", ou seja, na medida em que os sujeitos da pesquisa também elaboram hipóteses para explicar suas ações e testam, na prática, essas hipóteses? (Schön, 1996). Reconhece, como Pharo (1992, p. I 80), que "a maior parte dos conceitos de que dispomos (em sociologia) são conceitos de senso comum, e os que não o são ainda - porque são ou muito técnicos ou muito recentes - não tardarão a se tornar, uma vez que a vulgarização se efetue"?

No campo das ciências sociais e humanas, levar em conta o senso comum como um sistema coerente (Geertz, 1975) conduz à emergência de uma terceira via entre explicação e compreensão na pesquisa, que se situa "entre a prevalência da vivência e a prioridade à conceitualização" (Dosse, 1995, p. I3). Alguns autores já se engajaram nesta via: por exemplo, todo o trabalho de Boltansky, isolado ( 1990) ou em colaboração com Thévenot (1983; 1987), empenha-se em reavaliar a competência reflexiva dos não-especialistas, a capacidade do senso comum em ultrapassar os casos singulares e atingir uma forma de generalização. Pharo ( | 992, p. I | 9-30) justifica amplamente sua visão de que o saber sociológico tem um forte fundamento de senso comum. Essas correntes consideram que as competências cognitivas sobre a realidade não são mais exclusivamente atributo do pesquisador, colocando em questão a noção de corte epistemológico. Ricœur diz que "não há oposição entre a vivência e o conceito" (apud Dosse, 1995, p. 172-5) e Morin afirma que

...não há corte epistemológico radical. Não há uma ciência pura, não há um pensamento puro, não há uma lógica pura. A vida alimenta-se de impurezas, ou melhor, a realização e o desenvolvimento da ciência, da lógica, do pensamento, tem necessidade destas impurezas. (1996, p.34)

O pesquisador é assim convidado a fazer apenas obra de clarificação, a partir dos dados que thes são oferecidos pelos atores sociais. A colocação em evidência das capacidades reflexivas do senso comum é um convite ao questionamento da 
clivagem entre o pesquisador e seu objeto, entre saber científico e senso comum. Isso leva também a colocar em questão outro grande princípio da sociologia clássica, a saber, a posição naturalmente crítica, distante, do pesquisador que, apesar de se preocupar em desvelar a posição normativa do senso comum, nunca deixa claro seu próprio ponto de vista normativo. A importância atribuída a tais questões no contexto da obra de um autor mostra o tipo de diálogo que ele estabelece com seus informantes e o estatuto que lhes atribui no processo de produção do conhecimento.

\section{NO CENTRO DO TRIÂNGULO: RELAÇÕES DE PODER E PREOCUPAÇÃO ÉTICA}

Dois fatores situam-se no centro de nosso triângulo: as relações de poder e a preocupação com a construção de uma ética do processo de pesquisa. Sua posição central significa que, no nosso entender, tanto um quanto outro fator permeiam todos os aspectos e relações estabelecidas nesse processo. Se o primeiro fator já foi estudado de maneira mais detalhada, o mesmo não se passa com o segundo, que mereceu apenas considerações parciais. Com efeito, até agora, o estudo da dimensão ética no processo de pesquisa "se refere menos às condições de produção do saber do que às conseqüências de sua produção" (Encyclopédie philosophique universelle, 1990, p.887).

Como para as outras partes, tratamos aqui apenas de propor uma descrição do lugar da ética nas diversas práticas de pesquisa, restituindo-lhe assim um princípio de empirismo que se perdeu na forma abstrata sob a qual são geralmente tratadas as questões éticas. Desejamos ainda restaurar a dimensão histórica e coletiva da ética, na medida em que o grau de formalismo dos procedimentos de controle institucional na matéria difere de país para país ${ }^{8}$ e de grupo para grupo 9 .

Assim, ao tratarmos a ética como uma preocupação constante do pesquisador ao longo do processo de investigação, estamos buscando uma definição de ética que depende essencialmente das negociações que aí se estabelecem em vá-

8. A comunidade científica americana tende, nesse sentido, a ser mais prescritiva do que a francesa. Não somente os diversos grupos profissionais têm códigos de ética regulamentados; as universidades americanas instituíram comissões de ética que visam analisar os efeitos das pesquisas em ciências humanas e sociais sobre os sujeitos estudados.

9. Lembremos que, se os procedimentos de controle institucional são já tradição no campo das ciências exatas (Elias, 1983), as lutas para sua instauração estão ainda no início no campo das ciências humanas e sociais. 
rios níveis. Primeiramente, cabe descrever os pressupostos mais amplos que orientam a comunidade científica em seu conjunto - tendo-se em vista que a prática ética de cada pesquisador encontra sua legitimação na concepção ética prevalente na(s) comunidade(s) científica(s) à(s) qual(is) pertence. A seguir, no nível da corrente epistemológica na qual se inscreve, o pesquisador se depara com as definições éticas dos grandes paradigmas, com os comportamentos coletivos de seu grupo, expressos e legitimados tanto por meio da literatura produzida quanto pelas atividades científicas promovidas pelo grupo de pares. Em terceiro lugar, temos que considerar a negociação que ocorre na prática de pesquisa per se. Parece-nos oportuno ressaltar que esses diferentes níveis de negociação não se dão de maneira cronológica e seqüencial, mas se inter-relacionam a todo momento. $\bigcirc$ pesquisador vê-se constantemente questionando princípios preestabelecidos e construindo novos, ao mesmo tempo em que busca fundamentos teóricos e práticos para as negociações que desenvolve no processo de investigação.

Deter-nos-emos sobretudo no que se refere à dimensão cotidiana da ética de pesquisa - ou seja, o que chamamos acima de "prática de pesquisa per se". Desenvolvida pelas correntes qualitativas das ciências humanas e sociais, essa reflexão centra-se prioritariamente sobre as interações concretas entre o pesquisador e os sujeitos da pesquisa (instituições, grupos e indivíduos), quando da realização de estudos de campo. House ( 1990, p. 1 58), por exemplo, apresenta quatro princípios éticos básicos para a realização de estudos de campo nessa área: respeito mútuo, não coerção, não manipulação e suporte aos valores democráticos e às instituições. Esse autor afirma que uma quantidade ainda considerável de estudos realizados se mostra deficiente em pelo menos um desses três princípios ${ }^{10}$, apesar de todo o debate sobre a posição de poder atribuída ao pesquisador. No entanto, no nosso entender, um outro ponto-chave na ética das relações entre o pesquisador e o ator social tem sido sistematicamente ignorado: as formas pelas quais o primeiro deve devolver aos sujeitos de sua pesquisa a dádiva complexa que estes lhe fazem - de sua reflexão, palavra, prática e imagem (Brito, Vasquez, 1999). Brito (1994) pensa que os artigos científicos não bastam para que o pesquisador se desobrigue desse

10. Podem-se imaginar situações práticas em que a subscrição a esses princípios ideais - ainda que necessária - não seria suficiente para garantir o trânsito do pesquisador de maneira eficaz no campo. Muitas vezes, o que foi considerado uma invasão desrespeitosa em certos contextos não o seria em outros, na mesma época. O que é considerado ético no plano institucional ou público pode não ser viável no plano comunitário. Assim, a própria experiência do pesquisador tem um efeito retroativo na construção de sua ética no processo de pesquisa e suas experiências passadas servem de base para futuras negociações. 
imperativo (na medida em que são, no mais das vezes, escritos para a comunidade de pares) e sugere outras formas de fazê-lo, entre as quais uma discussão entre os dois interlocutores/atores do campo sobre a interpretação dos dados e os resultados obtidos, que se insere na perspectiva de uma construção intersubjetiva do conhecimento.

Mas a preocupação ética não se esgota na relação entre o pesquisador e os atores sociais. Na verdade, ela permeia toda e qualquer interação estabelecida durante o processo de investigação. Ela deveria começar por um processo de objetivação da própria posição do pesquisador, visto que só esse processo permite "que o pesquisador possa instituir uma distância com relação às dependências que atuam sobre ele sem que ele tenha consciência" (Chartier, 1983, p.IV): por exemplo, as influências das injunções da carreira ou dos ideais e exigências dos grupos com os quais ele se identifica.

Os pertencimentos, as posições e os interesses respectivos [de cada pesquisador] organizam não somente as posições ideológicas declaradas mas também - o que é mais interessante - as práticas científicas mais neutras e as decisões mais técnicas [como] a escolha e o recorte dos objetos, o modo de constituição e de tratamento dos dados, as formas de demonstração etc. (Chartier, 1983, p. IV, tradução nossa)

No que se refere à relação com a comunidade cientíica, a ética pode se expressar pela maneira como são utilizados os recursos da literatura científica: a maneira pela qual as idéias são referenciadas e os conceitos definidos, a proteção do princípio da autoria, a forma de citar suas fontes, entre outros.

As diversas possibilidades de combinação entre os elementos do triângulo centro, vértices e lados - permitem compreender melhor a complexidade da dimensão ética no processo de pesquisa qualitativa. Nesse sentido, temos alertado, ao longo deste texto, para a importância das diversas inter-relações que se estabelecem no processo de pesquisa e chamado a atenção para o grau variável de liberdade que podem assumir as relações aí estabelecidas.

\section{À GUISA DE CONCLUSÃO}

O principal argumento deste artigo é considerar que ainda seria prematuro propor um novo paradigma para as ciências sociais e humanas. Não se pode falar de consenso quanto à sua denominação ou quanto às suas formas de legitimação entre os adeptos das abordagens qualitativas de pesquisa. Pode-se certamente diagnosticar algumas convergências entre certas linhas de pesquisa, mas restam ainda 
muitos pontos a sistematizar antes que possamos falar com propriedade em um novo paradigma, entre os quais o lugar da "parte explícita e refletida da ação" (Dosse, 1995, p. 164) no processo de pesquisa, o estatuto da interdisciplinaridade (Morin, 1990; 1996) ou o " emprego de uma nova terminologia que redefina uma nova objetividade indissociável da intencionalidade e da subjetividade " (Dosse, 1995, p. 13). Por isso, preferimos no momento a via da descrição das práticas dos pesquisadores - sabendo que, dada a sua complexidade, a tarefa do conhecimento é muito mais coletiva do que individual e necessita ainda "do encontro, da troca entre todos os investigadores e universitários que trabalham nestes domínios disjuntos" (Morin, 1996, p.33).

A referência constante à necessidade de um paradigma ocultaria talvez, como sugere Schwandt (1995), o predomínio da visão positivista no seio de uma forma de pesquisa que visa, ao contrário, combatê-la. Mas seria bom não esquecer que essa referência oculta também uma luta de poder no interior do campo científico, na medida em que quem conseguir formalizar o paradigma poderá atribuir-lhe seu nome. Talvez a noção mesma de paradigma tenha que ser examinada mais de perto. Para alguns autores, como Gauchet (1988), "a fluidez relativa desta noção permite relativizar a influência de um modelo de explicação nas ciências humanas, que não é nem necessariamente uniforme nem utilizado por todos de maneira unívoca". Para outros, como Dosse (1995), ela encerra a idéia de momento, de geração, de uma mesma busca de sentido.

Uma outra questão que emerge no contexto é a função de um esquema como o triângulo que apresentamos acima -, dentro de um pensamento que se propõe a captar a complexidade do processo de pesquisa. $O$ leitor atento poderia perguntar-se se esse modelo relativamente simplista e bidimensional permite realmente alcançar uma descrição densa e complexa.

A resposta à questão comporta pelo menos dois argumentos. $\bigcirc$ primeiro apóia-se no fato de que o triângulo é, nesse caso, usado como a simples representação gráfica dos sistemas de relações entre os elementos do processo de pesquisa. No decorrer do artigo, podemos perceber que é praticamente impossível falar do poder do pesquisador sem nos referirmos aos sujeitos da pesquisa, falar de literatura sem evocar a comunidade científica, e assim por diante. Cada elemento encontra-se em uma relação multifacetada com os demais. É nesse sentido que inscrevemos nosso triângulo em um círculo, visando representar o processo de pesquisa em sua totalidade, que transmita a idéia de que cada um desses elementos está englobado em um todo maior, que possa ilustrar as relações e reciprocidades entre 
todos os níveis de análise. $\bigcirc$ triângulo que apresentamos neste texto não tem a pretensão de ser, como diz Morin, ao referir-se aos seus próprios esquemas, "um esquema de integração sintético e harmonioso; há nele brechas entre cada instância... O problema da epistemologia complexa é fazer comunicar estas instâncias separadas e, de certo modo, fazer o circuito" (1996, p.33). Além disso, ele não é a única forma gráfica possível de se montar um quadro analítico para a pesquisa qualitativa. Nós o escolhemos em razão do consenso existente sobre sua capacidade simbólica de exemplificar as relações complexas do processo de pesquisa, evitando o mais possível o reducionismo inerente às representações binárias antes praticadas. Talvez a melhor forma para representar essa complexidade, ainda latente em nossas comunidades científicas, fosse projetar o processo nas três dimensões do espaço: em vez de um triângulo inscrito em um círculo, poder contar com uma esfera na qual se inscrevesse uma pirâmide que girasse em todas as direções, de tal maneira que a alternância da posição de seus vértices pudesse representar a possibilidade de movimento e de atualização constante no seio do processo de pesquisa. No entanto, nosso desejo, ao abrir a discussão, não é que o leitor se atenha à forma gráfica de representação escolhida - amplamente justificada ao longo do artigo mas, antes, centrar o debate na imbricação existente entre as relações de poder inerentes a todo processo e à postura ética e teórico-metodológica do pesquisador.

O segundo argumento centra-se em nossa própria incapacidade de captar a complexidade. Nossas pretensões em captá-la não são apenas afetadas pela forma e pelas dimensões da representação gráfica. As dimensões binárias da folha de papel atuam aqui como um símbolo de nosso espírito, limitado por nossa inscrição no sistema binário de fazer ciência no qual fomos socializadas - o que torna extremamente difícil captar esta mesma complexidade a que aspiramos. Por mais que queiramos, como Elias ( 1983), desaprender as categorias mais habituais e os recortes mais tradicionais da ciência, somos ainda obrigadas, como Dufour (1989), a utilizar raciocínios causais, modelos e formas algorítmicas ainda fortemente tingidas de dualismo, na exposição de nossos trabalhos. Um pensamento verdadeiramente triangular, que enfatize as relações complexas dos elementos da realidade é "dificilmente assimilável no estado atual de nossa racionalidade" (Dufour, 1989, p. 134), mas, segundo Morin (1996, p.20), temos que nos esforçar para construí-lo "com a consciência de nossos limites e de nossas carências".

Esperamos que as críticas e sugestões que possam advir da leitura deste artigo sejam suficientemente construtivas para enriquecer a organização do campo da pesquisa qualitativa - seja ou não para se construir um novo paradigma. 


\section{REFERÊNCIAS BIBLIOGRÁFICAS}

ACKERMAN, W. et al. Décrire: un impératif ? Paris: Éditions de la Maison des Sciences de l'Homme, 1985.

ALLEN, B.; QIN, J.; LANCASTER, F.W. Persuasive communities: a longitudinal analysis of references in the philosophical transactions of the royal society, 1665-1990. Socia/Studies of Science. London: SAGE, Thousand Oaks and new Delhi, v. 24, p.279-310, 1994.

BOLTANSKI, L. L'Amour et la justice comme compétences. Paris: Metailié, 1990.

BOLTANSKI, L.; THÉVENOT, L. L'Économie des grandeurs. Paris: PUF/CEE, 1987.

. Finding one's way in social space: a study based on games. Socia/ Science Information, v. 22, n. 4-5, p. 631-79, 1983.

BOURDIEU, P. Champ de pouvoir, champ intellectuel et habitus de classe. Scolies I, I97I.

BOURDIEU, P.; PASSERON, J-C. La Reproduction. Paris: Minuit, 1970.

BOURDIEU, P.; PASSERON, J-C.; CHAMBOREDON, J-C. Le Métier de sociologue: préalables épistémologiques. 2.ed. Paris: La Haye, Mouton, 1973.

BRITO, A. La Construction de la relation entre le chercheur et son objet: une interprétation à la lumière de la théorie du don. Revue du Mauss, n. 4, 2ème. semestre, 1994.

BRITO, A.; VASQUEZ, A. Image as a symbolic gift . In: WALFORD, G.; MASSEY, A. (eds.). Studies in educational ethnography. London: Jai Press, 1999. v. 2. Explorations in methodology. p. $109-25$.

BULMER, M. The Chicago school of sociology. institutionalization, diversity, and the rise of sociological research. Chicago: The University of Chicago Press, 1984.

CAILLÉ, A. Critique de la raison utilitaire. Paris: La Découverte, 1989.

.Évolution générale. Faut-il créer une nouvelle discipline dans les sciences sociales et laquelle? (Pladoyer pour une philosophie politique qui aurait des allures de science). Revue du Mauss, n. 15-16 nouvelle série, p. II-42, ler. et 2ème. trimestres, 1992.

. Splendeurs et misères des sciences sociales. Genève: Droz, 1986.

CAPLOW, T.; McGEER, R. L. Publish or perish. In: GLASER, B. G. (ed.). Organizational careers, a sourcebook for theory. Chicago: Aldine, 1968. p. 227-9.

CHARTIER, R. Avant-propos. In: ELIAS, N. Engagement et distanciation. Paris: Fayard, I983, p. I-X.

CHÂTELET, F. (ed.). Histoire de la philosophie. Paris: Marabout, 1973. Tome 4, La philosophie au XX̀̀me siècle. 
DELEUZE, G. À quoi reconnaît-on le structuralisme?. In: CHÂTELET, F. (ed.). Histoire de la philosophie. Paris: Marabout, 1973. Tome 4. La philosophie au XXème. siècle. p. 293-329.

DERRIDA, J. Donnerle temps. I. La fausse monnaie. Paris: Galilée, 26, 1991.

DOBBERT, M. L. Discussion on methodology. In: GUBA, E. (ed.). The Paradigm dialog. Newbury Park, California: Sage, 1990. p. 283-9.

DOSSE, F. L'Empire du sens. Paris: Nathan, 1995.

DUBET, F. Texte de séminaire sur la méthode de l'intervention sociologique (inédit). Paris: CADIS, 1999.

DUFOUR, D-R. Le Structuralisme, le pli et la trinité. Le Débat, n. 56, p. 132-53, sept.-oct. 1989.

DUPUY, J-P. Ordres et désordres. enquête sur un nouveau paradigme. Paris: Seuil, 1982.

EISNER, E.; PESHKIN, A. A Qualitative inquiry in education: the continuing debate. New York: Teacher's college Press, 1990.

ELIAS, N. Engagement et distanciation. Paris: Fayard, 1983.

ENCYCLOPÉDIE philosophique universelle: les notions philosophiques, dictionnaire. Paris: PUF, 1990.

FEYERABEND, P. Contre la méthode: esquisse d'une théorie anarchiste de la connaissance. Paris: Seuil, 1979.

GAUCHET, M. Changement de paradigme en sciences sociales? Le Débatn. 50, mai-août. 1988. p. 165-70.

GEERTZ, C. Common sense as a cultural system. The Antioch Review, v. 33, n. I , printemps, 1975.

. La Interpretación de las culturas. Barcelona: Gedisa, 1990.

GODBOUT, J. (avec la coll. d'A. Caillé); CAILLÉ, A. L'Esprit du don. Paris: La Découverte, 1992.

GOETZ, J.; LECOMPTE, M. Ethnography and qualitative design in educational research. New York: Academic Press, 1984.

GUBA, E. The Paradigm dialog. Newbury Park, California: Sage, 1990.

Sorting out alternative paradigms for inquiry. Parameters and issues. Unpublished proposal for the International Conference on Alternative Paradigms for Inquiry, San Francisco, 1988.

HABERMAS, J. La Science et la technique comme idéologie. Paris: Gallimard, 1973. 
HOWE, K. R.; EISENHART, M. Standards for qualitative and quantitative research: a prolegomenon. Educational researcher, v. 19, n. 4, p. 2-9, 1990.

HOUSE, E. R. An Ethics of qualitative field studies. In: GUBA, E. (ed.). The Paradigm dialog. Newbury Park, California: Sage, 1990.

KAUFFMAN, J.-C. Conferência pronunciada no encerramento do colóquio Família e individualização. Paris: CERLIS, 7-9 out. 1999.

KUHN, T. La Tension essentielle: tradition et changement dans les sciences. Paris: Gallimard, 1990.

LECOMPTE, M. Bias in biography: bias and subjectivity in ethnographic research. Anthropology and Education Quarterly, v. 18, n. I, mar. 1987.

LEONARDOS, A. C. Opportunities to learn academic skills in the Brazilian public schools: a comparative case study. California, 1990. Tese (dout.) Stanford University.

LÉVY-LEBLOND, J-M.; JAUBERT, A. (Auto)Critique de la science. Paris: Seuil, 1975.

LINCOLN, Y.; GUBA, E. Naturalistic inquiry. California: Sage, 1985.

MORIN, E. Introduction à la pensée complexe. Paris: ESF, 1990.

. O Problema epistemológico da complexidade. Mem Martins (Portugal): Publicações Europa-América, 1996.

NOIRIEL, G. Pour une approche subjetiviste du social. Annales, nov.-déc. I 989. p. I 435-59.

PASSERON, J-C. La Logique des sciences sociales. pour un espace de raisonnement nonpoppérien. Paris: Fayard, 1991.

PATTON, M. Q. Qualitative evaluation and research methods. Newbury Park, California: Sage, 1990.

PESHKIN, A. The Researcher and subjectivity: reflections on an ethnography of school and community. In: SPINDLER, G. (ed.). Doing the ethnography of schooling. New York: Winston and Rinehart, 1982. p. 48-65.

. In Search of subjectivity: one's own. In: PESHKIN, A. The Color of strangers, the color of friends. the play of ethnicity in school and community. Chicago: The University of Chicago Press, 1991. p. 285-95.

PHARO, P. Phénoménologie du lien civil: sens et légitimité. Paris: L’Harmattan, 1992.

POPKEWITZ, T. S. Whose future? Whose past? Notes on critical theory and methodology. In: GUBA, E. (ed.). The Paradigm dialog. Newbury Park, California: Sage, 1990. p. 46-66.

QUÉRÉ, L. Le tournant descriptif en sociologie. Current Sociology, v. 40, n. I, printemps, 1992. 
SARTRE, J-P. Saint Gênet, comédien et martyr. Paris: Fayard, 1951.

SCHÖN, D. A. A La Recherche d'une nouvelle épistémologie de la pratique et de ce qu'elle implique pour l'éducation des adultes. In: BARBIER, J-M. (ed.). Savoirs théoriques et savoirs d'action. Paris: PUF, 1996. p. 201-22.

SCHWANDT, T. Farewell to criteriology, comunicação apresentada ao colóquio Quality in human inquiry, University of Bath, 14-17 mar. 1995.

SMITH, J. K.; HESHUSIUS, L. Closing down the conversation: the end of the quantitativequalitative debate among educational inquirers. Educational Researcher, v. 15, p. 4- 12, 1986.

SMITH, L. S. Ethics, field studies and the paradigm crisis. In: GUBA, E. (ed.). The Paradigm dialog. Newbury Park, California: Sage, 1990.

STENGHERS, I.; BENSAUDE-VINCENT, B. Histoire de la chimie. Paris: La Découverte, 1993.

TOURAINE, A. Le Retour de l'acteur. Paris: Fayard, 1984.

WEBER, M. Economia y sociedad. Mexico: Fondo de Cultura Económico, 1956. 